\title{
REVISIÓN SOBRE EL PROBLEMA DEL "DERECHO INJUSTO"
}

\section{Doctrinas que excluáan del concepto general del Derecho lodo contenido valorativo}

Desde fines del siglo xIx y hasta 1945, la mayoría de los filósofos del Derecho han distinguido con todo rigor dos temas diferentes: el tema del concepto universal o esencial de lo jurídico, por una parte; $y$, por otra parte, la cuestión estimativa o axiológica. La diferenciación y la independencia se deben a Stammler, quien estableció cor toda nitidez la distinción entre el concepto y la idea del Derecho; y reafirmadas por Del Vecchio, el cual sostuvo también la dimensión formalista del concepto del Derecho, precisamente porque mediante él se trata de obtener una noción universal, asunto diferente de la idea de la naturaleza como fundamento del Derecho, o sea del Derecho natural. Cierto que Del Vecchio incluye dentro del concepto universal del Derecho la nota de referencia intencional a la justicia, pero no el contenido de ésta. Separación similar se halla asimismo en la primera etapa de la filosofía jurídica de Radbruch, quien dio un concepto a priori y formal del Derecho, incardinado en el reino de la conducta que refiere hechos a valores, que relaciona acciones y obras con valores, aunque no sea necesario que los valores se den realizados, en suma, incardinado en el reino de la cultura, entendida ésta en el sentido de Windelband y Rickert. Y, así, Radbruch considera que la cultura abarca no sólo las virtudes, los conocimientos acertados, el Derecho justo de tal comunidad o de tal período, sino también sus vicios, sus errores, sus fracasos, sus frustraciones. Así, la cultura sería esa esfera cuyo carácter esencial consiste en ser una conducta referida a valores, independiente de que logre o no realizarlos, pero que contiene la intención de cumplirlos. Todo Derecho, justo o injusto, representa la intención de realizar un valor de justicia; podrá haberlo conseguido o no, pero el sentido de cualquier Derecho es el del desarrollo de la justicia. Es posible que en algunos casos la idea concreta que sobre la misma contenga sea precisamente una gran injusticia. A pesar de ello, dentro de esta legislación o de aquella costumbre monstruosa late la intención de representar una aplicación de la justicia; una intención, sin duda fracasada, pero una intención que es lo que da su sentido especial a lo jurídico. Llámase fenómeno cultural, según Radbruch, a un ser, en cuanto puede constituir objeto de una estimación, es decir, en tanto que es un sustrato posible de un valor o de un desvalor. Así, los actos que albergan una pretensión de justicia forman el Derecho; y Derecho, consiguientemente, es todo aquello que puede ser objeto de una apreciación de justicia o de injusticia. Derecho es 
aquello que debiera ser Derecho justo, séalo o no; Derecho es lo que persigue como fin la justicia, aunque para serlo no necesita de ningún modo haberla alcanzado. Lo jurídico equivale a ensayo (feliz o desgraciado) de ser (Derecho) justo.

Adviértase que en Stammler, Del Vecchio, Radbruch, cl concepto universal de lo jurídico es tratado como una categoría, en sentido kantiano - más o menos puro-, como una forma mental, para la ordenación de unos datos. Tales datos adquieren carácter jurídico, precisamente por quedar encuadrados dentro del concepto universal y formal del Derecho. $\mathrm{O}$ sea: los autores referidos, al igual que otros muchos --más o menos directamente conectados con ellos- desenvolvieron una teoría general del Derecho como una gnoseología o epistemología jurídica; y no en el plano ontológico, como lo he sostenido yo siempre.

Las notas de formalismo, neutralidad axiológica o estimativa, y gnoseologismo o epistemologismo las hallamos también, todavía mucho más acentuadas, en la concepción de Kelsen. En efecto, Kelsen arrancó de la concepción kantiana de que las formas mentales de conocimiento, los métodos, determinan a sus respectivos objetos: de que hay una estricta y rigurosa correlación entre el método y el objeto de conocimiento. La teoria pura del Derecho de Kelsen se reduce a una teoría general del Derecho, que quiere ser solamente una filosofía del método y de los conceptos formales básicos de la ciencia jurídica. Todo esto, claro, sobre supuestos filosóficos de linaje neokantiano. Según Kelsen, la depuración de la ciencia jurídica tiene que realizarse en dos direcciones: por una parte, frente a la tendencia ético-política, es decir, frente a la axiología o estimativa; y prescindir, por lo tanto, de las finalidades concretas a las que las normas jurídicas puedan servir; por otra parte, frente a la tendencia sociológica, que involucra hechos con normas, explicaciones causales con preceptos. El Derecho es Derecho no por virtud de una $u$ otra finalidad concreta, por su mejor adecuación a una idea ético-política, sino solamente por su especial forma normativa que es una normatividad coercitiva. La labor de la "teoría pura" deberá ser de tipo formal - prescindir de consideraciones teleológicas y sociológicas - por las razones siguientes: trátase de determinar conceptos universales, válidos para todo objeto jurídico; por consiguiente, cualquier alusión a un contenido concreto frustraría inexorablemente esa universalidad; no nos preguntamos acerca de cuál sería el Derecho mejor, sino tan sólo acerca del Derecho pura y simplemente, de su esencialidad universal.

Aunque ya desde mis primeras producciones filosófico-jurídicas, yo me emancipé de muchas de las dimensiones neokantianas - por ejemplo, del epistemologismo o gnoseologismo- y me plantee el problema del Derecho sobre el plano ontológico, sin embargo, todavía muy influido por las doctrinas de los autores que acabo de recordar, sostuve la neutralidad axiológica o estimativa de la noción esencial del Derecho, si bien incluyendo en la misma la referencia intencional a unos valores, con independencia de que éstos se hallen realizados o no realizados, mejor o peor realizados. 
$\mathrm{Y}$ a través de toda mi ulterior producción filosófico-jurídica hasta 1959 (inclusive) vine sosteniendo la misma tesis de que el concepto universal del Derecho no alberga dentro de sí contenidos axiológicos, sino tan sólo la mera referencia intencional a unos valores, pero no la realización efectiva de ésta.

Así, en mi Tratado General de Filosofía del Derecho digo lo siguiente. Adviértase que la noción esencial del Derecho a cuya búsqueda vamos, ha de ser una noción universal, dentro de la que quepan todas las manifestaciones de lo jurídico. El concepto universal del Derecho debe abarcar dentro de sí todos los Derechos que en el mundo han sido, todos los que son y todos los que puedan ser. Este concepto debe darnos la esencia de lo jurídico, pura y simplemente, dejando a un lado todos los calificativos específicos e individuales que correspondan a manifestaciones jurídicas de diversas clases. Debe ser un concepto que sirva lo mismo para el Derecho civil que para el penal, el procesal, el constitucional, etc.; que sea igualmente aplicable al ordenamiento e instituciones de un pueblo primitivo y al Derecho complicado y refinado de un Estado civilizado de Occidente; valedero tanto para el Derecho antiguo como para el medioeval, el moderno y el contemporáneo. $\mathrm{Y}$, por tanto, también, que comprenda igualmente las normas jurídicas justas como asimismo las normas jurídicas injustas.

Y yo seguía haciendo las siguientes reflexiones. Nadie se sienta alarmado por esto último, es decir, porque se hable de Derecho injusto. Tal expresión, que acaso pudiera parecer a primera vista paradójica o incluso absurda, no tiene nada de ilógico, antes bien, corresponde a la debida caracterización de múltiples realidades y posibilidades. Cierto que -según veremos- corresponde esencialmente al Derecho la intención de orientarse hacia la realización de unos valores, es decir, pertenece a la esencia misma del Derecho el pretender ser justo. Pero lo que pertenece a la esencia de lo jurídico es solamente esa intención de justicia y no su logrado cumplimiento. $O$ dicho con otras palabras: son diversos el tema de la definición y el tema de la valoración. Ambos constituyen cuestiones legítimas y obligadas para la Filosofía del Derecho. Esta debe ocuparse de la definición esencial de lo jurídico; y debe estudiar además también los criterios estimativos, a cuya luz podemos enjuiciar los ordenamientos positivos históricos y hallar las pautas para una progresiva reelaboración del Derecho. Ahora bien, hay una distinción perfectamente clara entre estos dos temas, aparte de que entre ellos puedan mediar conexiones filosóficas de otro género. En efecto, una cosa es preguntarnos por lo que es Derecho pura y simplemente, como una especial zona o forma de la vida humana; y otra cosa diferente es inquirir por los valores o ideales en que el Derecho debe inspirarse para que sea justo.

$\mathrm{Y}$ en apoyo de esta tesis, yo aducía que, por desagradable que ello resulte, no cabe duda de que ha habido y hay normas e instituciones jurídicas injustas, verbigracia: la institución de la esclavitud (racimo de gravísimas injusticias), múltiples leyes soviéticas, fascistas y nazis (conglomerados de las más antihumanas monstruosidades). Ahora bien, adviértase que la institución de la esclavitud 
es estudiada en la historia del Derecho y no en la historia de otra rama de la cultura (no en la historia del arte, no en la historia de la ciencia, no en la historia de la cocina, etc.). Por injusta no deja la esclavitud de pertenecer al mundo jurídico de la Antigüedad Clásica. Ni la esclavitud, ni algo muy parecido o acaso peor como son los campos soviéticos de trabajo forzado, ni las leyes racistas de los nazis son cosas que se estudien en la historia de la literatura, de la pintura, de la ingeniería, etc. Son estudiadas en la historia del Derecho, porque constituyen instituciones jurídicas, aunque monstruosas y repugnantes, las más abominables que hayan existido jamás, sin duda alguna.

Y para apoyar esta tesis añadía yo que la adscripción de un producto de la vida humana a un sector o a otro de las funciones que integran ésta, no se determina por el grado del logro de los valores correspondientes que aquel producto haya conseguido. Al concepto de Arte y a la historia de éste pertenecen no sólo las manifestaciones artísticas logradas, sino también las frustradas; pertenece toda obra humana en la que se quiso encarnar un sentido de belleza, lo mismo si esto se logró que si se frustró. Al concepto de Ciencia y a la historia de ésta corresponde registrar no sólo la obtención de verdades, sino también todos los ensayos de conseguir la verdad que naufragaron en el error. Por consiguiente, el concepto esencial de Derecho ha de comprender no sólo los ensayos jurídicos logrados, sino también los fracasados. La pertenencia de una obra humana al campo jurídico no se decide por la consecución efectiva de justicia que haya logrado encarnar, sino por la posesión de una serie de caracteres formales, que son los que determinan o constituyen la esencia de lo jurídico. Similarmente, la atribución de un producto al concepto de Ciencia, o al concepto de Arte, no depende de que él haya realizado en efecto valores estéticos o respectivamente lógicos, sino en la concurrencia de una serie de notas formales. Gierto que entre esas notas formales, que son esenciales, figura la referencia intencional a los valores correspondientes. Es decir, para que algo merezca la denorninación de Ciencia, aunque sea de ciencia errónea, es preciso que constituya un propósito de conocimiento verdadero, justificado, etc. Para que algo caiga dentro del concepto de arte se requiere que signifique una intención de dotar de belleza formal una representación. Para que algo sea incluido dentro de lo jurídico, es menester que posea una serie de notas formales, entre las cuales figura la intención de constituir la interpretación de las exigencias de la justicia con respecto a unas determinadas relaciones sociales.

Así pues, decía yo, que el hecho de que reconozcamos como legítimo y obligado este tema de la definición esencial del Derecho, la cual tiene tan sólo un alcance de concepto lógico y de determinación ontológica, pero no el de un juicio estimativo, no implica, de ninguna manera, que no admitamos la otra investigación, a saber: la investigación sobre los valores jurídicos, sobre la justicia y sobre los ideales en que el Derecho debe inspirarse; antes bien, hay que proclamar que, sin perjuicio del estudio sobre la esencia formal de lo jurídico, es la indaga- 
ción sobre la justicia, sobre el criterio valorador del Derecho, sobre el Derecho natural, el tema más importante de la filosofía jurídica. $Y$, asimismo, que reconozcamos que ha habido, hay y puede haber Derecho injusto, no supone ningún ademán de conformidad ante esa desgracia o ese ultraje; antes bien, ello es perfectamente compatible con proclamar, como creo que es obligado hacerlo, que debemos luchar denodadamente contra el Derecho injusto, hasta conseguir su corrección o reforma, o, si necesario fuere, su derrocación por todos los medios, incluida la violencia.

En otro lugar escribí que hay que subrayar que el Derecho, que es una obra humana de forma normativa, la objetividad de una especial forma de existencia colectiva, se orienta esencialmente hacia unos valores. Ahora bien, esos valores pueden resultar cumplidos en unas concretas normas jurídico-positivas o, por el contrario, hallar en ésta sólo una realización parcial, o no conseguir su encarnación en ellas. El contenido o las exigencias de esos valores no pueden entrar dentro de la definición esencial del Derecho, sencillamente porque conocemos Derecho logrado, es decir, satisfactoriamente justo, Derecho menos justo, y Derecho frustrado o injusto; y en todas ellas hallamos las notas formales de la juridicidad.

Y al ocuparme de dar una rigorosa e irrebatible justificación de la meditación axiológica o estimativa sobre el Derecho, he escrito: "Los ingredientes del Derecho positivo no son todos ellos positivos, sino que hallamos la referencia intencional a algo no positivo. Aunque la norma de Derecho positivo emane de un mandato, de un poder efectivo, no puede de ninguna manera ser entendida como un mero hecho, pues es un hecho humano, y, a fuer de tal, tiene sentido o significación. $\mathrm{Y}$ ese sentido consiste cabalmente en la referencia a unos valores, en la pretensión de una justificación: se manda esto y no aquello, porque quienes lo determinan creen que esto está justificado; creen que esto es preferible a lo demás, $\mathrm{y}$, por ello, lo eligen entre todas las otras posibilidades concretas. $\mathrm{O}$, dicho de otra manera: la normatividad del Derecho positivo no tendría sentido, si no se refiriese a un juicio de valor que es el que la inspira. Se regula la conducta social de un determinado modo, porque se cree que este modo es mejor que otras posibles regulaciones. Desde luego, cabe que el Derecho positivo fracase en su intento; el panorama de la historia ofrece abundante repertorio de leyes y de costumbres injustas. Pero incluso en éstas late la intención de realizar un valor, aunque lejos de haberlo logrado hayan fracasado, a veces totalmente. Se trata entonces de una intención fracasada; pero, en tanto que intención, existe esencialmente como sentido de la norma. La mera noción del Derecho positivo, aunque no contiene dentro de sí el ideal jurídico, sin embargo, lo presupone, es decir, postula su existencia; se refiere intencionalmente a él, aunque no acierte a realizarlo en algunos casos. No cabe entender el sentido de lo jurídico si prescindimos de la referencia a ideales de justicia. No es que la definición del Derecho contenga esos ideales en su seno; porque si fuese así, perdería su intención de univer- 
salidad. Pero si bien la definición del Derecho no alberga dentro de sí los supremos valores jurídicos, sin embargo, los mienta, se refiere a ellos intencionalmente. Si borrásemos del Derecho positivo esa mención de principios no positivos, no nos quedaría de él nada más que un conglomerado caótico de puros hechos incomprensibles, de simples relaciones de poder, cuando no de fuerza."

$\mathrm{Al}$ sostener esta tesis, jamás intenté transigir con ninguna injusticia monstruosa. Por el contrario, siempre he sostenido la más radical oposición a las injusticias abominables que registra la historia del Derecho, tales como las siguientes: la esclavitud, la Inquisición, los campos de concentración de trabajo forzado, acertadamente llamados campos de la muerte, establecidos por los bolcheviques en 1920 y copiados después por los nazis, los regímenes totalitarios (soviético, fascista y nazi) las discriminaciones odiosas, las condiciones injustas de trabajo, etc.

$\mathrm{Y}$ al estudiar la producción originaria de Derecho, en los casos de solución de continuidad en la historia jurídica por causa de una conquista, una revolución o un golpe de Estado, he sostenido que el reconocimiento o comprobación de que ha nacido un nuevo Derecho no implica necesariamente, de ninguna manera, ni un juicio valorativo favorable a lo que haya creado la conquista, el golpe de Estado o la revolución triunfante, ni muchísimo menos que se tenga que bajar forzosamente la cabeza ante los hechos consumados. Puede reconocerse que ha nacido un nuevo Derecho y estimar, sin embargo, que, por ser éste tan abominable, se tenga el deber de hacer todos los esfuerzos para derrocarlo, incluso acudiendo a la violencia. Es decir, se puede registrar la legalidad de hoy; y luchar por sustituirla en el mañana con una legalidad más justa, bien reanudando la de ayer, bien estableciendo otra nueva sobre bases mejores.

\section{Crisis de la separación radical entre el concepto general del Derecho y el contenido valorativo}

Desde la terminación de la Segunda Guerra Mundial se ha producido una crisis en muchos iusfilósofos ilustres que otrora habían sostenido la diferencia tajante entre la noción universal o esencial de lo jurídico, noción puramente formal, por una parte, y, por otra parte, los criterios estimativos o axiológicos que deben inspirar al orden jurídico. Algunos filósofos del Derecho, por ejemplo Radbruch, quienes antes habían sostenido aquella tajante diferencia, en sus publicaciones a partir de 1945, rectificaron en el sentido de no admitir que puedan ser consideradas como "Derecho" unas normas cuyo contenido sea monstruosamente injusto, como son las de los Estados totalitarios (comunistas, fascistas y nazis) y que sólo puede ser tenido como Derecho un orden de normas que reconozcan la dignidad de la persona humana individual y las libertades básicas de ésta. Otros iusfilósofos, que han desempeñado y desempeñan papel prominente en el pensamiento de nuestros días, a partir de 1945, por ejemplo, Hans Welzel defienden también esta tesis. 
Independientemente del juicio que tal tesis pueda merecernos y de la solución a que después de un análisis crítico podamos llegar, es preciso reconocer que tal doctrina, en el modo como se ha manifestado a partir de 1945, constituye la reacción espiritual contra las escalofriantes atrocidades que encarnan en los Estados totalitarios; y significa también una reacción superlativamente enérgica contra cualquier clase de positivismo jurídico. Cierto que nada de positivismo jurídico había ni en Del Vecchio ni en Stammler ni tampoco en mí mismo. Pero hoy muchos pensadores entienden que el dar una noción exclusivamente formalista del Derecho en todo caso significa un contagio - aunque muchas veces inconsciente- del positivismo jurídico; y consideran que el positivismo jurídico constituyó un clima que, aunque sin proponérselo, hizo posible la aparición y el desenvolvimiento del monstruo totalitario.

La reacción filosófico-jurídica contra las atrocidades espeluznantes del Estado totalitario se ha producido en dos direcciones, las cuales, aunque en muchos autores muestran nexos recíprocos, son sin embargo independientes desde un punto de vista estrictamente teórico. En primer lugar, la trágica experiencia del Estado totalitario ha estimulado fuertemente un segundo renacimiento de la preocupación por el Derecho natural. En segundo lugar, por otra parte, ha planteado el tema que analizo en el presente estudio: el tema de si cabe o no, de si es admisible o no, un concepto puramente formalista del Derecho, una definición de la esencia de lo jurídico, que no contenga dentro de sí algún criterio estimativo o axiológico.

Es muy probable que los nuevos iusnaturalismos, por una parte, $y$, por otra, la revisión crítica del concepto formalista del Derecho sean dos pensamientos íntimamente emparentados en la producción filosófico-jurídica de los últimos veinte años. No obstante, se trata de cuestiones independientes, por lo menos en alguna medida. Que es así lo muestra una serie de doctrinas producidas en el primer tercio del siglo $\mathrm{xx}$ en las cuales se propugna decidida y terminantemente una estimativa o axiología jurídica, incluso tesis francamente iusnaturalistas, por una parte; $y$, sin embargo, por otra parte, en la teoría general del Derecho se sostiene la necesidad de que el concepto universal de lo jurídico sea puramente formalista y no albergue dentro de sí contenidos valorativos. Esto es lo que sucedió con las doctrinas de Stammler, Del Vecchio, Verdross (en la primera etapa de su pensamiento), Legaz y Lacambra, García Máynez, yo mismo, etc. Estos pensadores, mencionados aquí tan sólo como unos pocos ejemplos, pero también otros muchos más, sin perjuicio de haber desarrollado una estimativa o axiología jurídica - algunos de ellos con clara tendencia iusnaturalista-, en otra parte de la filosofía del Derecho, en la habitualmente llamada teoría general o fundamental del Derecho, han admitido no sólo la posibilidad, sino que además han afirmado la necesidad, de que la noción universal de lo jurídico sea un concepto formalista, que no albergue criterios valorativos, precisamente'por las ra- 
zones que antes expuse, las cuales se resumen en el propósito de que tal concepto sea totalmente universal.

Resulta, pues, claro, que muchos iusfilósofos sostenedores y constructores de una estimativa o axiología jurídica, e incluso de una doctrina de Derecho natural, consideraron que esto era compatible con un carácter de formalismo neutral en la elaboración del concepto universal del Derecho, o sea de la noción esencial de lo jurídico, pura y simplemente, sin adjetivos de ninguna clase, ni siquiera adjetivos de valoración.

El segundo renacimiento del iusnaturalismo - con signos diferentes: renovaciones a fondo de la dirección neo-aristotélico-tomista; otros de inspiración por el pensamiento protestante; otros conectados con bases existencialistas; otros, influidos por una especial interpretación de la filosofía fenomenológica de los valores; otros, entrelazados con análisis sociológicos; etc.-, podría haber constituido eso y nada más que eso, es decir, una vigorosísima restauración con largo alcance de direcciones iusnaturalistas. Si hubiese sido así, si lo acontecido hubiera sido tan sólo eso, entonces a la historia del iusnaturalismo en el siglo xx antes de 1945, después de ese año habría que añadir una lista de nuevas y renovadas producciones de Derecho natural. Así, la formidable obra del teólogo calvinista Emil Brunner. Así, las nuevas contribuciones, llenas de lozanía, de inspiración neotomista, de Messner, Verdross (en la última fase de su pensamiento), Maritain, Husson, Leclerq (en sus últimas obras), Villey, Legaz y Lacambra (en la postrera reelaboración de su doctrina de la desnormatización del Derecho natural) Ruiz Giménez (con su existencialismo neotomista), Agustín de Asis, Corts, Truyol, Preciado Hernández, González Díaz Lombardo, Kuri Breña, Basave Fernández del Valle (existencialismo católico), González Uribe, Porrúa Pérez, Villoro Toranzo Rodríguez-Arias Bustamante, Betancur, Naranjo Villegas, Pacheco Gómez, Caldera, Calvani, Merea, etc. Así: el Derecho natural de Coing (como valores éticos que deben ser atribuidos esencialmente al Derecho), en algún modo influido por Scheler y N. Hartmann, y en cierto modo también de Llambías de Azevedo. Así también: los iusnaturalismos con raíz existencialista, más o menos próxima o más o menos remota, de Jaspers, Maihoffer, Fechner, y también de Welzel (aunque él no se considere a sí mismo como iusnaturalista). Asimismo: el Derecho natural fundado en la filosofía de la acción de Perticone, la nueva axiología culturalista de Bagolini, la doctrina de la validez intrínseca de García Máynez, la estimativa del valor de la persona humana de Reale. También en el mundo de lengua inglesa, entre otras, las siguientes contribuciones: la doctrina sobre "el sentido de la injusticia" de Cahn, el nuevo iusnaturalismo de Bodenheimer, la nueva defensa del iusnaturalismo por Lon Fuller, la teoría sobre los postulados universales de justicia de Brecht (publicada también en alemán, lengua materna del autor), las "Mansiones de la Justicia" de Julius Stone, etc.

Aunque a mi temperamento repugna toda exhibición erudita, sin embargo, venciendo mi renuencia a caer en ella, he creido conveniente presentar aquí 
algunos nombres muy representativos de los múltiples y variados renacimientos iusnaturalistas en nuestros días. He incluido la mención de algunos pensadores, los cuales, ellos, no admitirían este calificativo, pero que a mi modesto entender pueden ser incluidos dentro de ese múltiple y variado movimiento de restauración de la estimativa jurídica con signo de un nuevo segundo retorno en este siglo hacia el Derecho natural o hacia algo parecido a éste.

$\mathrm{Y}$ creo que, a pesar de las importantes diferencias, algunas de largo alcance, entre las doctrinas de los autores que acabo de mencionar, todos elios en alguna medida han sido influidos por el sentimiento de que es imperativo reaccionar contra el Estado totalitario. Esto se hace manifiesto con superlativo relieve sobre todo en los autores alemanes que sufrieron la barbarie integral del régimen nazi, y que todos los días reciben a refugiados que escapan del totalitarismo comunista, del cual por otra parte tienen testimonio muy próximo en los desmanes cometidos por las autoridades de la Zona Soviética en la parte de Alemania mal llamada "República Democrática" o."Alemania Oriental"; y en Italia que durante tantos años sufrió la plaga del fascismo. Pero en toda la parte civilizada del mundo, es decir, en el mundo libre, que no sufrió antaño bajo el totalitarismo, pero que sufrió la Segunda Guerra Mundial desencadenada por el pacto nazi-soviético, se ha suscitado una nueva vocación por el Derecho natural en la conciencia de los hombres que, aunque pecadores, desean seguir viviendo una existencia propiamente humana y no simplemente animal.

Por debajo de todas las doctrinas aludidas, creo que hay un denominador común, a saber, el siguiente pensamiento: si el Derecho fuese única y exclusivamente el resultado de los factores de poder político, nada más que la expresión de la voluntad de quienes consiguieron el gobierno después de haber embriagado a las masas con mitos detestables, o por haberse encaramado violentamente a los resortes de mando mediante golpes de fuerza, o por haberse infiltrado a traición en posiciones claves, entonces, hablar de atrocidades o de injusticia carecería de todo sentido. Si el Derecho fuese única y exclusivamente la resultante de un mero fenómeno de poder político, entonces no habría en absoluto ningún fundamento para la crítica o protesta contra los asesinatos en masa llevados a cabo por los regímenes comunista, fascista y nazi. Entonces, sería irracional protestar contra el hecho de que el Estado soviético o el Estado nazi intente la degradación integral de sus súbditos, contra el hecho de que desconozcan y nieguen toda dignidad de la persona individual, contra el hecho de que supriman de raíz las libertades básicas - como la de conciencia, culto, pensamiento, educación, movimiento, inviolabilidad del hogar, elección de oficio o profesión, etc. Sería irracional protestar por el hecho de que el Estado totalitario intente apoderarse no sólo de una parte de la conducta externa de sus súbditos (lo cual en fin de cuentas hace todo Estado y todo orden jurídico), sino también de sus almas, de su pensamiento, de su conciencia. Todos esos hechos y otros de similar índole podrían ser simplemente lamentados por las víctimas, deplorando éstas el 
que en la lotería del juego de las fuerzas políticas tuvieron mala fortuna y les tocó estar abajo. Pero toda crítica o protesta no tendría base ninguna sobre la cual apoyarse. Quien sufre los efectos del rayo fulminador, de la inundación devastadora o del huracán que arruina, puede llorar su mala suerte; pero si está en el uso cabal de sus funciones mentales, no tendrá la ocurrencia de "protestar" contra tales sucesos aciagos. Pero claro que no es eso lo que una conciencia normal siente y piensa ante los desmanes de los dictadores totalitarios. La crítica, la protesta, la rebeldía, la revolución, se engendran no por el hecho de padecer un espantoso dolor; sino por el hecho de considerar que se es víctima de una tremenda injusticia. Sufrir bajo las fuerzas de la naturaleza suscita aflicción. Pero sufrir por obra de la injusticia provoca indignación. El entrometimiento injusto del poder público en la vida personal, que debe ser un sagrario o un castillo en el cual jamás pueda entrar la autoridad política, se experimenta como un atentado intolerable.

Cierto que siempre ha habido injusticias, pero nunca existió en la historia de la humanidad una época como la que se inicia en 1917 en que en la zona totalitaria se haya producido la injusticia elevada a principio rector. La injusticia como desconocimiento de los criterios que deben regir el orden jurídico, o como defectuosa aplicación de éste, es lamentable. Pero lo que se ha producido y se produce bajo cualquiera de los regímenes totalitarios de los tres tipos -soviético, fascista y nazi, los cuales en cuanto a sus efectos prácticos se parecen superlativamente- es algo muchísimo más grave: es la injusticia total elevada a principio, convertida en factor permanente. El totalitarismo constituye no un enorme número de injusticias, sino la negación terminante de todo principio de justicia, la negación de los derechos básicos de la personalidad humana, el convertir a los ciudadanos en simple pasta para la edificación de una deleznable fantasmagoría política; el utilizar a los hombres como simple alfalfa para alimento del monstruo estatal.

Así se explica que la experiencia del Estado totalitario haya provocado una intensa reafirmación vigorosa de los valores jurídicos, especialmente en la forma de una reiteración de los derechos naturales básicos de la persona humana.

Ahora bien, el tema del presente estudio no es un relato de ese segundo renacimiento iusnaturalista, múltiple y muy variado producido después de la Segunda Guerra Mundial. El tema del presente trabajo es otro: la cuestión de si podemos o no seguir insistiendo en una definición meramente formalista del Derecho, como concepto universal de éste, o si, por el contrario, hemos de revisar este problema.

Sucede que, paralelamente a ese nuevo renacimiento iusnaturalista, o por lo menos de axiología jurídica, producido a partir de 1945 - poco más o menos-, muchos destacadísimos iusfilósofos de nuestros días se han planteado ese problema, sobre si la definición universal del Derecho debe ser por entero formalista, o si, en cambio, debe albergar algún contenido axiológico o estimativo. 
Pero antes de proceder sumariamente al relato de las nuevas tesis de que la definición esencial del Derecho debe comprender algún contenido axiológico, y no sólo una mera referencia intencional -como lo habíamos sostenido Del Vecchio y yo-, es de justicia recordar que ésta ha sido una doctrina ininterrumpidamente sostenida por los neo-escolásticos y también por otros autores antes de 1945.

Como muy representativa de la posición neoescolástica, citaré aquí lo que sobre este punto dice Preciado Hernández. "El deber ser que prescribe una norma no se funda en meros hechos o decisiones volitivas, sino en una ley ética que enuncia una relación necesaria moralmente, una jerarquía ontológica de bienes humanos, y una adecuación de actos a fines valiosos." "El sentido común se resiste a atribuir la calidad de jurídicas a aquellas disposiciones que, aun cuando proceden de quienes ejercen el poder público, van en contra de lo que prescribe la razón. . L La razón descubre que el hombre es un autofín, una persona a la que no se debe tratar como cosa, convirtiéndola en un medio o simple instrumento, a la que en todo caso se debe respetar y tomar en cuenta su eminente dignidad y sus prerrogativas esenciales, y que, por eso mismo, la esclavitud es contraria a la naturaleza humana. Sin embargo, en pleno siglo veinte, un poder dictatorial ha impuesto un régimen de esclavitud para los prisioneros de guerra; ¿ puede calificarse este régimen de jurídico?... En esos casos estamos en presencia de un poder social que impone, efectivamente, reglas a la actividad de los hombres. Pero ni aquél es autoridad, ni éstas son normas jurídicas. Los fuertes pueden, de hecho, dominar y destruir a los débiles... ; pero estos hechos, como tales, no son jurídicos, no están regidos por normas sino por leyes cosmológicas; se explican, mas no se justifican."

Pero no han sido sólo los filósofos de inspiración neotomista los únicos que sostuvieron esa doctrina de que el concepto del Derecho debe comprender algún contenido axiológico. Una tesis similar ha sido mantenida por otros autores, ya antes de la Segunda Guerra Mundial; por ejemplo: por Ravá, Solari, Capograssi, y también por otros varios.

Adolfo Ravá se negó a considerar el concepto del Derecho como una forma vacía. Por el contrario, lo piensa como un modelo con contenido normativo. El problema sobre la justificación del Derecho, aunque distinguible del problema sobre la definición del Derecho, es inseparable de éste. La justificación del Derecho no puede separarse de su definición, porque no se trata de comprender, sino de regular; porque el Derecho no es una forma intelectiva, antes bien, una forma regulativa o normativa. Aunque Ravá pertenezca a una dirección neokantiana, rechaza las doctrinas de Cohen, Natorp y Stammler y se sitúa más cerca de Windelband y de Rickert, y se aproxima tal vez más a Fichte, para quien a la razón práctica le corresponde el primado sobre la razón teorética. Ravá considera que el Derecho es un valor, un criterio valorador de las acciones humanas, si bien no constituya propiamente una norma ética, sino solamente técnica, pues no juzga del bien en sí, sino de la adecuación respecto de un fin justo que se 
quiera alcanzar. Pero dentro de ese fin debe figurar la protección del desarrollo autónomo y de la libertad de los individuos. El Derecho es una norma técnica, que continuamente pone o expresa exigencias éticas.

Para Solari el Derecho es sobre todo y esencialmente libertad. Solari ataca la diferencia establecida por Del Vecchio entre el concepto y el ideal del Derecho; y sostiene la eticidad del Derecho y del Estado, un poco a la manera neo-hegeliana. Pero, en todo caso, Solari mete dentro del concepto del Derecho valores objetivos.

Capograssi, quien ha desarrollado una filosofía de la acción, divide la ley de ésta en dos: la ley jurídica y la ley moral. El sujeto agente está amenazado por el mal no sólo en tanto que agente, sino que además el mal amenaza también la acción. La ley jurídica quiere salvar la acción, en tanto que el imperativo moral permite salvar al agente. El imperativo jurídico se convierte en coeficiente esencial para el desarrollo ético de la persona, pues es entonces cuando la voluntad se mira más a fondo a sí misma, se encara con sí propia. La historia de la experiencia jurídica es la historia de la fidelidad de la voluntad a sí misma.

\section{Nuevas revisiones críticas sobre la definición formalista del Derecho}

Desde la Segunda Guerra Mundial hasta su muerte, acaecida en 1949, Radbruch derivó hacia la afirmación de una postura iusnaturalista, o, por lo menos, muy próxima al Derecho natural.

"La ciencia del Derecho debe reflexionar nuevamente sobre la milenaria sabiduría que afirma que existe un Derecho superior a la ley, un Derecho natural, un Derecho divino, un Derecho racional, según el cual la injusticia es siempre injusticia, aun cuando a esta injusticia se la moldee en las formas de una ley." Además, Radbruch terminó por abandonar el dualismo metodológico en Derecho, consistente en separar entre el ser y el deber ser y rechazó la posibilidad de un concepto puramente formal de lo jurídico. A este resultado contribuyó también la idea que últimamente desenvolvió sobre la naturaleza de la cosa o de la situación objetiva, que es el camino que se ofrece a todos quienes se esfuerzan en atenuar el dualismo entre realidad y valor, a quienes buscan la razón en las cosas o en las realidades.

Helmut Coing considera que el Derecho es una creación del hombre, pero no una arbitraria creación, sino una creación que sirve a determinados fines éticos, y que tiene un determinado círculo de objetos y que constituye un fenómeno social en el que se dan unas ciertas exigencias éticas. Los dos datos del Derecho son: en primer lugar, unos valores éticos que el Derecho debe realizar; en segundo término, la naturaleza de las cosas. El Derecho esencialmente se encamina a la paz social mediante un orden que afirme la libertad. El Derecho protege la esfera vital de cada individuo y la de cada grupo de la comunidad política, las cuales se definen mutuamente, según reglas universales. El Derecho sirve para la afirmación del yo, pero no sin tomar en consideración a los demás. Así, el 
Derecho recibe su significado desde una pluralidad de finalidades y valores. Tiene que establecer la paz, el orden y la seguridad; también tiene que ordenar situaciones justas, garantizar la libertad y ayudar a la victoria de la buena fe en los negocios. La relación de estas finalidades se puede aclarar mejor con la metáfora de los niveles: sobre la base de un orden simple de paz se sobrepasan otros niveles del Derecho, segura y moralmente determinados. Estas finalidades no tienen necesariamente que ser realizadas todas a la vez; algunas pueden destacarse, otras pueden postergarse. En ciertas situaciones también pueden estar en contradicción: la seguridad del Derecho puede contradecir a la justicia social, o la libertad a la buena fe. Tales conflictos son inevitables. El material que se tiene que ordenar pone límites al orden jurídico. Este material es la vida social, condicionada por la naturaleza del hombre y del mundo en el que éste vive. Los límites que se refieren al material pueden resumirse en el concepto de la "naturaleza de las cosas". Pero lo que encontramos aquí es, en el fondo, la naturaleza del hombre y de su vida espiritual y física en su medio ambiente.

Algunas ideas de Jaspers han influido en la obra de varios iusfilósofos alemanes contemporáneos. Sostiene Jaspers que para comprender la esencia del Derecho es preciso tener en cuenta una doble circunstancia: por una parte, la existencia del hombre sólo puede afirmarse en sus decisiones individuales y conscientes, por lo cual cl Derecho posee únicamente una significación mediata en el orden de la existencia. Pero, por otra parte, el Derecho, ordenamiento que hace posible la coexistencia humana, es necesario a la vida, ejerciendo un influjo reflejo sobre la afirmación de la personalidad. La validez de forma y ley no es una simple validez externa para quien vive en el principio del ser; su acatamiento no es un mero formalismo, sino la cosa misma, cuya rigidez determina que no pueda ser lesionada. El hombre responsable exige, no un orden cualquiera, sino una ordenación que respete y proteja los derechos del hombre, condición básica de la decisión existencial. Y Jaspers enumera una serie de principios sobre los derechos básicos del ser humano, que pertenecen a la esencia misma del Derecho.

Fechner intenta llegar a una definición total del Derecho, para lo cual utiliza en parte los métodos de la fenomenología. Entiende que los enfoques positivistas, naturalistas, historicistas y sociológicos son parciales. Es parcial tanbién la visión que quiere deducir desde arriba, partiendo de una especie de espíritu absoluto, determinados criterios jurídicos, sea situando éstos en un reino ideal, sea en un ambiente estrictamente racional, sea en un mandato divino. La consideración exclusiva de los factores reales, al igual que la mera meditación sobre puras ideas, no explican, ni la una ni la otra, la totalidad del Derecho. Sin embargo, todos esos factores participan en la constitución del Derecho.

Fechner ha utilizado la concepción ontológica estratificada de la realidad de Nicolai Hartmann: cada capa ontológicamente superior tiene sus propios principios, categorías y leyes, pero, a la vez, se apoya o encuentra su soporte 
en el estrato inferior (y con él en todos los más bajos) y lo absorbe. Cada estrato posee su propio orden de índole distinta, y representa algo nuevo en comparación con el estrato inferior. En el ser todo hay orden; pero ese orden es multiforme. Ahora bien, el Derecho constituye una especie de sección de ese orden total: es una de las partes del orden que rige las relaciones sociales. En tanto que tal, el Derecho está afectado por los diferentes estratos del ser, y atraviesa éstos verticalmente, participando de la objetividad propia de ellos. El Derecho aparece como un orden en el que está inserto el hombre; porque el hombre es hombre, sólo a través de las dimensiones de ese orden. Su libertad y dignidad consisten en conocer y reconocer las dimensiones de ese orden. Análogamente a los conceptos y a las leyes del pensamiento, las proposiciones jurídicas no son construidas, sino más bien reconstruidas, reelaboradas, no son fabricadas, sino que son halladas.

Según Fechner, el Derecho es un producto necesario, fundado en la esencia del ser humano social. Como exteriorización esencial del hombre, el Derecho participa en el carácter enigmático del ser humano. Las dos preguntas sobre qué sea el hombre y sobre lo que sea el Derecho apuntan parejamente a una realidad básica, la cual puede ser circunscrita y adivinada, pero nunca puede ser determinada y concebida exhaustivamente y de un modo exactamente racional.

Ahora bien, según Fechner la pregunta sobre lo que propiamente sea el Derecho es idéntica con el problema del Derecho natural. Nos encontramos con la oposición entre dos concepciones: la concepción trascendente idealista y a priori, frente a la explicación naturalista, empírica y a posteriori. La primera de estas concepciones, con todas sus diversas variantes, considera que el Derecho se funda en un orden obligatorio, en unos criterios objetivos ultrapositivos, que pueden ciertamente expresarse de manera diversa según la época y según el lugar, pero que tienen intrínseca validez y que obligan a todos los hombres; de suerte que un Derecho positivo que contradiga esos criterios debe ser considerado como algo antijurídico. Por el contrario, según la segunda concepción, es decir, la positivista, los ordenamientos jurídicos son la obra de los hombres que fabrican el Derecho (de los hombres más poderosos dentro del grupo), quienes configuran las normas jurídicas de acuerdo con las necesidades de la situación empírica, y muchas veces de acuerdo con los puntos de vista del poder político que predomina. Ahora bien, Fechner, sin negar la diferencia entre la idea del Derecho (Derecho natural) y el concepto del Derecho, sin embargo, cree indispensable incluir dentro del segundo, esto es, dentro del concepto, la función esencial del Derecho, la cual consiste en crear un orden justo, nota que es precisamente la que le otorga la dimensión de lo jurídico.

En alguna medida, podría caracterizarse el pensamiento de Hans Welzel, con el título de uno de sus libros Más allá del Derecho natural y el positivismo jurídico. Welzel suministra argumentos decisivos contra toda forma de positivismo jurídico, argumentos que no es pertinente reproducir aquí. Baste con 
mencionar la observación de que el jurista tiene que ir más allá del mundo conceptual del positivismo, a fin de buscar ideas trascendentes que confieran seguridad y universalidad a sus afirmaciones. Para hallar la esencia del Derecho, el cual es una ordenación social de lo humano, hay que tomar en cuenta esos dos elementos: la ordenación y lo humano. Lo segundo es lo que lo define con carácter de permanencia. En tanto que ordenación, el Derecho tiene como nota esencial su carácter de poder conformador o configurador de la realidad social. Esto es, la positividad. Pero esa función que el Derecho ejerce dc configurar la realidad, vale como tal, sólo cuando confiera seguridad social, es decir, cuando libere $y$ proteja al individuo del caos colectivo. Por otra parte, aunque Welzel niega la existencia de valores universales independientes de toda condicionalidad histórica, afirma, en cambio, como esenciales al concepto de Derecho unas estructuras lógico-objetivas, que están dadas de antemano al legislador, y que deben fijar los límites de su libre actividad creadora. Que el jurista reconozca en el orden positivo el primer valor elemental del Derecho, la seguridad, no significa de ninguna manera que este orden real pueda tener cualquier contenido. La teoría de la omnipotencia jurídica del legislador es el verdadero pecado original del positivismo jurídico. Superar ese pecado es la tarea principal del futuro. El legislador debe estar sujeto siempre a determinados límites inmanentes al Derecho positivo.

La primera limitación se encuentra en aquellas estructuras lógico-objetivas que atraviesen integramente la materia jurídica, prescribiéndole una regulación de determinado tipo. Si desconoce o viola esas estructuras, entonces no será propiamente Derecho. Nadie puede modificar la naturaleza de las cosas. Quien quiera imponer normas a la acción, tiene que presuponer la estructura categorial del hacer humano; ningún legislador puede modificarla. Sobre esta estructura se puede, desde luego, formular declaraciones de validez universal; muy especialmente en lo que se refiere a la función y a la posición de la voluntad en la estructura de la acción. Aquí ni la ley ni la ciencia tienen ningún poder de disposición. Ahora bien, entre estas estructuras está, como la más importante y como fundamento de todas las demás, la autonomía ética del ser humano. El Derecho no es simplemente un poder configurador de la realidad social, sino que lleva además en sí mismo una dimensión valorativa. Los valores no son esencias ideales absolutas, puesto que de éstas es imposible deducir conclusiones concretas. Los fines del actuar humano no están constituidos por valores abstractos sino por bienes concretos. Sucede que el bien concreto supremo del actuar humano es la autonomía ética, la cual permite al ser humano alcanzar, independientemente de toda vinculación de medio y fin, un sentido terrenal propio de validez intemporal. Esta autonomía debe ser respetada como principio fundamental, alrededor del cual pueden establecerse otros principios relativamente concretos. La autonomía ética es lo que da al individuo el carácter de persona; $y$ es al hombre, en tanto que persona, a quien se dirige el Derecho, exigiendo 
acatamiento como poder obligante, ya que el hombre, en tanto que persona (como fin en sí, ético), es el contenido material mínimo de la ética.

En resumen, dice Welzel, que, si bien es cierto que el Derecho no puede prescindir de la positividad, en tanto que ordenación social, esta última debe a su vez respetar las estructuras lógico-objetivas que limitan el actuar jurídico, y la dimensión valorativa, hacia el cual apunta siempre el iusnaturalismo. Sin positividad, el Derecho es simple abstracción o aspiración ideal de un orden posible. Sin su nota axiológica fundamental (autonomía ética de la persona) es mera fuerza incapaz de cumplir con el postulado de toda ordenación: la protección del ser humano. Por consiguiente, no es orden jurídico, no es Derecho, el ordenamiento que no reconozca y proteja la autonomía de la persona. Si el Derecho es un orden obligatorio, entonces hemos de reconocer que al hombre se le puede obligar, sólo en tanto que persona. Pero entonces el Derecho, para que sea tal, tiene que reconocer al hombre como persona. En el reconocimiento, tácitamente presupuesto, del hombre como persona reside la diferencia decisiva entre el Derecho y el simple poder.

También Mario de la Cueva sostiene que no puede haber un orden jurídico, digno de este nombre, esto es, que sea jurídico, si no constituye una regulación de la conducta de personas, entendiendo por persona, el individuo dotado de dignidad, esto es, que tiene fines propios suyos, y que jamás debe ser degradado a la condición de mero medio.

Ya desde sus primeras publicaciones, Felice Battaglia combatió la tesis de Del Vechhio de que puede darse un concepto del Derecho como una mera forma a priori indiferente de su contenido. Por el contrario, Battaglia estimó que era necesario averiguar cuál sea el principio por virtud del cual se constituye la experiencia jurídica, y que anima y suscita, promueve y constituye, alimenta y estimula el mundo jurídico, real y variado. $Y$ cada vez ha acentuado más Battaglia que el Derecho no es una forma externa capaz de captar cualquier contenido para sí, sino que es un principio ontológico, pletórico de contenido, y presente en toda la experiencia que podamos calificar como jurídica. La juridicidad objetiva se constituye por el hecho de que el yo individual y el tú individual se presentan como universales, a través de recíprocos reconocimientos mutuos, que son, en tanto que tales, éticos.

Perticone señala que hoy en día vivimos no sólo un nuevo renacimiento del Derecho natural, sino además también otra cosa: la revitalización de un símbolo, de una bandera, de un ideario de la libertad y de la justicia, que nos lleva a negar valor y validez al principio, a la norma, al imperativo que no realicen los valores de libertad y justicia, entendiendo éstas no tan sólo en sentido formal, antes bien, con contenido.

Según Luigi Bagolini, la definición del Derecho ha de ser una definición valorativa, es decir, implicar un criterio de justicia. Así pues, una definición general del Derecho implica valoraciones en términos de justicia. Esto no signi- 
fica que una definición del Derecho sea una definición de la justicia. Pero no es posible un discurso júrídico rigoroso que no implique premisas concernientes a aquello que se podría llamar un paradigma o un modelo de Derecho.

\section{Titubeos por los que ha pasado el autor del presente estudio}

Yo confieso que mi conciencia teórica ha pasado por una serie de dramáticos titubeos, al afrontar la contraposición entre una definición meramente formalista del Derecho (sin perjuicio de admitir y propugnar una estimativa o axiología jurídica), por una parte, y las nuevas reacciones antiformalistas de los últimos veinte años, las cuales incluyen criterios axiológicos en el concepto universal o esencial de lo jurídico.

Cierto que yo nunca caí en un formalismo de tipo neokantiano como el de Stammler; ni tampoco discurri jamás por la línea ortodoxa el-formalismo neopositivista de Kelsen, sin perjuicio de reconocer, por otra parte, inmensos logros conseguidos por su obra. Pero, en cambio, desde mis mocedades hasta hace poco tiempo, sí estuve honda y sólidamente persuadido de la posibilidad, aún más, de la necesidad, de un concepto universal del Derecho, de una noción esencial de lo jurídico, la cual precisamente para ser universal, no podía albergar dentro de sí juicios de valor, sino tan sólo la mera referencia intencional a unos valores específicos; es decir, estuve firmemente convencido por la tesis de Del Vecchio sobre este punto.

Sucedió, empero, que, por vía simpática, las espantosas aberraciones del Estado totalitario produjeron una honda mella en mi conciencia, y determinaron que yo mismo me volviese a plantear' el problema de si puede o no aceptarse la tesis que antes había sostenido de que la definición universal del Derecho debía ser puramente formalista - aunque contuviese la mención intencional hacia unos valores. Por otra parte, las nuevas obras de filosofía del Derecho producidas poco más o menos después de 1945 produjeron también un fuerte impacto en mi conciencia teorética, inclinándome decididamente a la revisión crítica de este punto.

Sin embargo, el proceso de esa revisión crítica en mi propio pensamiento ha sido algo lento. Por una parte, yo comprendía que era necesario negar el carácter de Derecho a los ordenamientos inhumanos de la Unión Soviética y de sus colonias (los llamados países satélites), de la Italia fascista, de la Alemania nazi, de la China comunista, y de la Cuba castrista.

Por otra parte, sin embargo, todavía seguían pesando mucho en mi ánimo los argumentos que yo mismo había empleado profusamente para defender la dimensión puramente formalista del concepto universal de lo jurídico, o sea de la noción esencial del Derecho. Recuerdo sobre todo aquellos argumentos de que la esclavitud, síntesis de las más monstruosas injusticias, se estudia siempre en la historia del Derecho, sin perjuicio de reconocer los horrores de esta institución. 
Y seguía pesando todavía más sobre mi conciencia teórica la siguiente consideración: si metemos dentro del concepto del Derecho los criterios axiológicos que deben inspirar a éste, entonces, puesto que en el mundo no ha habido ni hay Derecho perfectamente justo, sino a lo sumo, en los mejores de los casos, Derecho relativamente justo, satisfactoriamente justo, pero nunca de un modo absoluto, tendríamos que llegar a la conclusión de que en la realidad ni ha existido ni existe Derecho, puesto que no podríamos encontrar un orden jurídico total e inobjetablemente justo.

La segunda de estas consideraciones podía superarse más fácilmente. En efecto, esa reflexión podía ser inocuizada diciendo que la introducción en el concepto del Derecho de criterios axiológicos no tenía que implicar necesariamente una perfecta realización o un pleno cumplimiento de éstos, sino tan sólo una realización de los mismos en la medida relativa de lo viable. A este respecto, recuerdo un agudo pensamiento de Salvador Laborde Cancino, de que $e_{\perp}$ " rho de que no sea posible hallar un orden jurídico totalmente justo, pues los meju. entre todos los ordenamientos jurídicos arrastran consigo algún margen de pequeñas injusticias, no impone que de la noción universal del Derecho queden excluidos criterios axiológicos. Laborde ilustra esta opinión suya, diciendo lo siguiente: el único metro verdadero, el único metro auténtico, es la dimensión de la barra de platino iridiado que se halla en el pabellón de Breteuil en Sévres, mientras que los instrumentos de medida, supuestamente de un metro, existentes en las tiend, - por ejemplo de telas- son tan sólo aproximaciones de aquel metrc sulno, y, sin embargo, admitimos como buenas tales aproximaciones; " Lando después un sesgo irónico a la ilustración de este pensamiento, Laborde añadía que estamos habituados a aceptar muchas veces en los comercios kilos de novecientos ochenta gramos, o incluso de menos. Pero, en cambio, nadie aceptaría, como un metro, setenta centímetros y mucho menos cuarenta; ni como un kilo ochocientos gramos o menos. De la misma manera, aceptamos como jurídicas muchos normas que arrastran consigo un pequeño margen de injusticia; mas, por el contrario, no debemos considerar como jurídicas normas atroces que nieguen la dignidad de la persona humana individual y sus libertades fundamentales.

En esa tesis de Laborde hay una buena inspiración aprovechable. Pero lo que no me parece ya tan admisible es que se tome como criterio una pauta simplemente cuantitativa. Y si, hipotéticamente - tan sólo a los efectos de la discusión- aceptáramos un punto de vista cuantitativo, entonces surgiría el problema, por cierto muy grave, de determinar el límite de esa medida cuantitativa.

De otro lado, a pesar de esas objeciones que brotaban en mi ánimo, mi conciencia no podía sustraerse a los efectos provocados por el horripilante totalitarismo.

El problema se complicaba dentro de mi ámbito subjetivo por el hecho de que no es fácil echar por la borda una tesis que uno ha venido manteniendo durante casi cuarenta años. Claro que siempre me he esforzado por evitar que 
mi pensamiento cristalice en formas fósiles. Por el contrario, he puesto siempre máximo empeño en dejar abierto mi propio pensamiento para todas las revisiones críticas que sean suscitadas bien por una nueva reflexión propia, bien por nuevos hechos que choquen con doctrinas adoptadas antes. $Y$ si alguien se ha tomado la molestia de haber seguido el desarrollo de mi propio pensamiento, habrá advertido que en el mismo se han ido produciendo sucesivamente virajes y modificaciones de bastante alcance. Pero declaro que la tesis de que la definición esencial del Derecho debía ser puramente formal -a pesar de que yo no figurase en una tendencia de formalismo en filosofía del Derecho, sino todo lo contrario-, me era superlativamente satisfactoria, o, mejor dicho, me había resultado aceptable, hasta el momento en que brotaron en mi ánimo las dudas suscitadas por los factores que ya he relatado aquí.

Pero después de darle muchísimas vueltas, y más vueltas, a este problema, me parece que he llegado a una solución satisfactoria que permite incluir criterios axiológicos dentro de la definición esencial de lo jurídico, sin perjuicio de que esa definición continúe aspirando a un alcance general.

Desde luego no vamos a negar el carácter de jurídico a un ordenamiento que contenga dentro de sí algunas injusticias, mayores o menores, pero que no contradigan diametralmente los valores jurídicos supremos. Pero, en cambio, era preciso encontrar una razón plenamente justificada para negar carácter jurídico a los ordenamientos de los Estados totalitarios, a la esclavitud, a la Inquisición, y a otras monstruosidades que registra la historia, no sólo del pasado, sino, incluso -en gran tamaño-, del siglo xx.

5. Ensayo de solución, que introduce un contenido valorativo sin mengua de la "universalidad" del concepto del Derecho

Me parece que por fin he podido hallar un criterio claro para negar que las normas que contienen esas horripilantes injusticias, que acabo de recordar, sean Derecho. $O$, lo que es lo mismo, creo que he encontrado cuál es el crịterio axiológico que debe ser contenido por el concepto general del Derecho o noción de la esencia de lo jurídico. Se trata de un criterio preciso, diáfano, de claros perfiles, sin ninguna difuminación. Tal criterio consiste en añadir a las notas formalistas de lo jurídico la siguiente dimensión: la de que sean normas (con un específico carácter coercitivo o disposición inexorable, etc.), reguladoras de la conducta de personas humanas en tanto que personas. Voy en seguida a dar las razones justificadoras para incluir esa nota axiológica de contenido en la definición universal del Derecho. Pero antes deseo hacer constar que para la elaboración de esta tesis he hallado fecundos estímulos en pensamientos de Welzel, Fechner, y de Mario de la Cueva.

La dificultad para resolver el problema que teóricamente me ha estado agobiando durante algunos años, consistía en lo siguiente: consideraba yo que no 
debía renunciarse al propósito de establecer un concepto auténticamente universal de lo jurídico, una noción genuinamente esencial del Derecho. Para lograr esto era necesario evitar la inclusión de cualquier determinación concreta o particular dentro de tal noción o concepto, es decir, persistir en el propósito que había animado a Stammler, Del Vecchio y a mí mismo. Pero, por otra parte, consideraba yo indispensable, al igual que muchos de los pensadores actuales que he citado, incluir un contenido axiológico en ese concepto. Ahora bien, este propósito me parecía llevar a un callejón sin salida, por virtud del prejuicio que todavía pesaba sobre mí de que cualquier adjetivación dentro del concepto del Derecho iba a privar a éste de la dimensión de universalidad o de esencialidad, y llevar a una confusión entre el mero concepto del Derecho y las ideas de valor que el Derecho debe realizar.

Pero creo que modestamente he encontrado el camino para la solución de ese problema. Persisto en establecer un concepto esencial o universal del Derecho, sin adjetivos. Pero sucede que el Dercho en tanto que norma se dirige a la regulación de la conducta de seres humanos. Entonces resulta que esta noción esencial ha de contener dentro de sí precisamente tal nota, a saber: que se trata de regular la conducta de seres humanos lo cual equivale a decir de personas humanas en tanto que tales, esto es, en tanto que sujetos intrínsecamente dotados de dignidad, o lo que es lo mismo de sujetos que tienen fines propios, que son cada uno de ellos en sí mismo un fin, o lo que es lo mismo un autofin, para emplear la formulación kantiana de la dignidad.

Si unas normas coercitivas, de imposición inexorable, bilaterales, etc. (añádanse los otros caracteres formalistas del Derecho), establecen la esclavitud, instituyen la Inquisición, niegan la libertad de conciencia, la autonomía personal para decidir sobre el propio estado civil y para elegir profesión u oficio, impiden la libertad de movimiento, o atentan contra cualquiera otra de las libertades fundamentales de la persona humana individual, entonces ésas no son unas normas reguladoras, de la conducta de seres humanos, sino unas normas reguladoras del comportamiento de seres degradados a la condición de simples animales.

Persisto en el propósito de no confundir entre concepto general o esencial del Derecho y valores jurídicos que deben inspirar a éste. Persisto en distinguir entre concepto e idea del Derecho. Persisto en diferenciar entre teoría general o fundamental del Derecho y estimativa o axiología (o Derecho natural). Persisto en reconocer que el contenido plenario de la justicia y de todos los requerimientos que de ésta derivan no puede albergarse dentro de la noción general o esencial de lo jurídico. Pero, en cambio, he llegado a convencerme de que sólo pueden ser consideradas como normas jurídicas aquellas que además de reunir las características formales (bilateralidad, coercitividad, socialidad, etc.), sean normas que regulen la conducta de seres humanos, reconociendo a éstos precisamente como humanos, es decir, como sujetos intrínsecamente dotados de dignidad, o lo que es lo mismo, como personas. 
Después de haber hallado este criterio axiológico como nota esencial de lo jurídico, caigo en la cuenta de que si prescindiéramos de tal nota, las normas colectivas de imposición inexorable o coercitivas, bilaterales, etc., que no reconociesen a sus destinatarios como personas humanas, como sujetos dotados de dignidad, como autofines, entonces esas serían unas normas que presupondrían como destinatarios a simples animales. Introducir dentro del concepto formal del Derecho la dimensión esencial de que las normas jurídicas están destinadas a seres humanos y deben tratar a éstos en tanto que tales, y no como simples bestias, no constituye una adjetivación particular o concretante que prive a la noción de lo jurídico de su pretensión de universalidad. Tal nota es una dimensión general de lo juridico. Cuando unas normas, aunque se hallen dotadas de los caracteres de socialidad, bilateralidad, impositividad inexorable o coercitividad, etc., no tratan a sus destinatarios como personas humanas, entonces nos hallamos ante normas que no son jurídicas, a pesar de que reúnan las otras características formales del Derecho.

Una norma jurídica relativamente injusta, que haya en alguna medida fracasado en su propósito de justicia en cuanto a la materia o relaciones interhumanas que intenta regular, pero que no desconozca la dignidad de los sujetos obligados y de los autorizados, esa norma será una norma jurídica deficiente, menos justa, pero, en fin de cuentas, jurídica. Por el contrario, una norma dictada por la autoridad competente, con los caracteres de socialidad, bilateralidad, impositividad o coercitividad, etc., que niegue la libre concesión de pasaporte para salir del país a sujetos que no tengan pendientes cuentas con la justicia o con el cumplimiento de su servicio militar, esa norma no es jurídica porque trata a sus destinatarios no como seres humanos, no como personas dotadas de dignidad, sino como puros animales de tiro, como simples bestias de carga, que es a lo que equivale decir que no se les concede permiso para salir del pais a pretexto de que la economía nacional los necesita.

Una norma que niegue la libertad de conciencia, aunque esa norma sea dictada por una autoridad competente y tenga los caracteres de impositiva 0 coercitiva, etc., no es una norma jurídica porque trata a sus destinatarios no como seres humanos, sino como simples objetos, como meras cosas al servicio de una voluntad ajena.

No hay, pues, una identificación entre el concepto general o esencial de lo jurídico y lo que se denota con la expresión Derecho natural. No se trata de esto. Podemos constatar muchas e incluso graves divergencias entre el Derecho positivo de un pueblo en un cierto momento histórico y lo que entendamos como exigencias de justicia o como consecuencias de principios iusnaturalistas; pero si tales divergencias no implican la negación de la calidad de persona a los destinatarios de la norma, ni niegan a éstos los derechos básicos del ser humano, entonces tendremos que reconocer como jurídicas esas normas, a pesar de sus defectos. Pero si, por el contrario, nos hallamos en la presencia de normas 
- como sucede con muchísimas de las normas de los Estados totalitarios- que no reconocen a sus sujetos destinatarios como seres humanos, como personas con dignidad intrínseca, entonces eso no es Derecho; entonces no decimos\&que eso sea Derecho injusto o menos justo, sino pura y simplemente que no es Derecho. Porque entonces habremos introducido dentro del concepto general o esencial del Derecho, incluso podríamos seguir diciendo formal, que el Derecho está integrado por normas que quieren como destinatarios a seres humanos en tanto que humanos, es decir, que tienen como destinatarios a personas con dignidad - con todas las consecuencias necesarias que de la dignidad dimanan.

Esta nueva doctrina, que esbozo aquí, nos lleva inevitablemente, a la nececidad de distinguir en el conjunto de las normas que tengan la mera apariencia de formalmente válidas, unas como jurídicas, y otras, a pesar de aquella apariencia, como no jurídicas, como no incluibles dentro del concepto general del Derecho.

Yo no digo que todas las normas dictadas por los Estados totalitarios no sean normas jurídicas. Ciertamente que no son jurídicas las normas más importantes de esos regímenes totalitarios, porque ellas implican esencialmente la negación de la dignidad del ser humano. Similarmente frente al cuerpo total de lo habitualmente llamado "L "cho Romano" deberemos discriminar entre normas auténticamente jurídicas (más o menos justas) y normas que a pesar de que estén incluidas en ese cuerpo no son propiamente jurídicas, "cual las relativas a la esclavitud.

Con esta nueva tesis rectifico lo que durante muchos años sostuve en mis sucesivos libros de filosofia del Derecho. Ahora bien, lejos de lamentarlo, dentro de la medida de mi modestia, me siento muy satisfecho por ello, incluso me atrevería a decir que me siento orgulloso, por razón de esta rectificación de una parte de mi teoría fundamental del Derecho, tal y como ésta apareció en su última versión en mi Tratado General de Filosofía del Derecho. 